\title{
Refractory Lymphocyte-Depleted Classic Hodgkin Lymphoma
}

National Cancer Institute

\section{Source}

National Cancer Institute. Refractory Lymphocyte-Depleted Classic Hodgkin Lymphoma. NCl Thesaurus. Code C8650.

Lymphocyte-depleted classic Hodg kin lymphoma that is resistant to treatment. 